\title{
Provenance by Site Interaction of Pinus densiflora in Korea
}

\author{
By In-Sik KIm ${ }^{1), *}$, Hae-Yun Kwon ${ }^{2)}$, Keun-OK RYu ${ }^{2)}$ and Wan Yong $\mathrm{CHOI}^{2)}$
}

(Received $26^{\text {th }}$ October 2006)

\begin{abstract}
Thirty-six provenances of Pinus densiflora were evaluated for stability and adaptability for height growth at 11 test sites in Korea. The data were obtained from measurements at age 6 and analyzed using linear regression model and AMMI (additive main effect and multiplicative interaction) model. There was significant provenance by site interaction effect $(p<0.011)$. The interaction term explained $7.1 \%$ of total variation. While the regression model accounted for $15.8 \%$ of $\mathrm{GxE}$ interaction term, the AMMI model accounted for $74.9 \%$ with four PCA values. Most of the provenances were not significantly different from the unity $(b=1.0)$, except for Inje (1), Jungsun (4), Bongwha (5), Koryung (26), Hamyang (30) and Seoguipo (36). Adaptability of provenances to the test sites was estimated with mean height growth and first AMMI component scores (IPCA 1). Inje (1), Bongwha (5), Taean (20) and Seoguipo (36) were specifically adapted to the high yielding environments. Considering the first and second AMMI components (IPCA 1 and IPCA 2, respectively) scores, Whachun (2), Samchuk (10), Joongwon (14) and Buan (29) provenances were more stable than others. The implication of $\mathrm{GxE}$ interaction was discussed in view of seed transfer and delineation of seed zones.
\end{abstract}

Key words: linear regression model, AMMI model, provenance test.

\section{Introduction}

Pinus densiflora is naturally distributed in temperate regions of Korea, Japan and eastern China (RICHARDSON and RunDEL, 1998). In Korea, $P$. densiflora is an important timber species and the most widely distributed conifer species (LEE and CHO, 2001). Its range extends from Hambuk province in North Korea to Jeju province in South Korea. Although it is observed at alpine region, their main distribution range is low to moderate elevation (Korea Forest Research Institute, 1999). It often forms pure stands along the mountain ridges and slopes but sometimes forms mixed stands with hardwood species in Korea.

There are much variation of growth characteristics among $P$. densiflora provenances and great potential for selection and breeding, i.e., tree form (UYEKI, 1928), biomass production (PARK and LEE, 1990) and wood quality (YIM and LEE, 1979; KIM et al., 2002). Other researchers

\footnotetext{
1) Forest Seed Research Center, Korea Forest Research Institute, 670-4 Suheori, Suanbomyun, Chungju, Chungbuk 380-941, Republic of Korea.

2) Tree Breeding Division, Korea Forest Research Institute, 44-3 Omokchun, Kwonsun, Suwon, Kyonggi 441-847, Republic of Korea.

*) Author to whom all correspondence should be addresses: IN-Sik Kim. Phone: +82 43850 3332, fax: +82 438482902 . E-mail: kimis02@forest.go.kr
}

also reported that there are remarkable genetic variation in inter and intra populations of $P$. densiflora using isozyme and DNA markers (KIM et al., 1995; LEE et al., 1997).

A range wide provenance test for $P$. densiflora was established in 1996 by the Korea Forest Research Institute to address seed transfer zoning and to determine the suitable seed sources for reforestation programs. KIM et al. (2005) reported that temperature, humidity and annual mean growing days of test sites were positively correlated with survival rate and height growth. A considerable amount of variation in survival rate and height growth was explained by latitude, annual mean growing days, extreme low temperature (Dec. Feb.) and extreme high temperature (Nov. Feb.) of provenances. These results were obtained from four test sites representing the cool-temperate, mid-temperate, warmtemperate and sub-tropical zones in Korea, respectively. However, the magnitude and pattern of genotype by environment interaction for $P$. densiflora has not yet been reported.

In tree improvement, the $\mathrm{GxE}$ interaction is an important consideration, as both its magnitude and its pattern have profound implications for breeding, testing, and seed deployment (JOHNSON and BuRDON, 1989; CARson, 1991). The existence of $\mathrm{GxE}$ interactions calls for the evaluation of genotypes in many environments to determine their true genetic potential (CHAHAL and GosAL, 2002). Thus, an assessment of stability (or adaptability) and $\mathrm{GxE}$ interaction is fundamental to the development of a sound seed movement policy (YEISER et al., 2001).

The GxE interaction may be defined as the inconsistent relative performance of two or more genotypes over two or more environments (YeISER et al., 1981). Genotype by environment interaction may be due to heterogeneity of variance measured at each of the sites, where ranking of genotypes in various environments is unaffected or due to both heterogeneity of variances and rank changes (DiCKERSON, 1962).

Analysis of stability and adaptability is a biometrical method with great potential for characterization of the relative performance of a group of population (families, varieties, hybrids, lines, clones, etc.) under different environmental conditions (VIANA and CRUZ, 2002). The detection and quantification of $\mathrm{GxE}$ interaction has been attempted through four different statistical approaches, i.e., partitioning of variance, regression analysis, non-parametric statistics and multivariate technique (CHAHAL and Gosal, 2002).

In analysis of variance, the interaction between genotypes and environments contribute to the total variance which is estimated and tested for statistical significance. 
Each of variance components not only reflects the nature of genotype by environment interaction but helps to devise suitable selection and testing strategy to avoid or utilize these interactions for the development of suitable types of provenances (IsIK et al., 2000). Regression analysis is based on the concept that the component of a genotype by environment interactions are linearly related to environmental effects measured as the average performance of all test genotypes for the character under consideration (FINLAY and WILKINSON, 1963). In

Table 1. - The location of 36 provenances of Pinus densiflora.

\begin{tabular}{|c|c|c|c|c|}
\hline \multirow{2}{*}{ Provenance } & \multicolumn{3}{|c|}{ l.ocation } & \multirow{2}{*}{ Forest zone } \\
\hline & I. $4 t(N)$ & l.ong.(W) & Alt. $(m)$ & \\
\hline 1. Іṇje & $38^{\circ} 08^{\prime}$ & $128^{\circ} 12^{\prime}$ & 400 & \\
\hline 2. Whathun & $38003^{\prime}$ & $127^{\circ} 49^{\prime}$ & 150 & \\
\hline 3. 1tongchun & .37046 & 128025 & 700 & cool-temperate \\
\hline 4. Jungsur & $37^{\circ} 31^{1}$ & $1288^{\circ} 2^{1}$ & 600 & \\
\hline 5. Bongwhat & $37^{\circ} 01^{\prime}$ & $128^{\circ} .50^{\prime}$ & 500 & \\
\hline 6. Yeonchun & $38^{\circ} 01^{\prime}$ & $127^{\circ} 04^{\prime}$ & 100 & \\
\hline 7. Ileungsung & $37^{\circ} 32^{\prime}$ & $127^{\circ 5} 1^{\prime}$ & 300 & \\
\hline 8. Ichun & $37^{\circ} 15^{\prime}$ & $127^{\circ} 20^{\prime}$ & 150 & \\
\hline 9. Chunan & $36^{\circ} 47^{\prime}$ & $127^{\circ} 20^{\prime}$ & 100 & \\
\hline 10. Samcluuk & $37^{\prime \prime} L 5^{\prime}$ & $129^{\circ} 17^{\prime}$ & 100 & \\
\hline 11. Uljin-seo & $36^{\circ} 58^{\prime}$ & $129 \% 13$ & 500 & mid-temperale \\
\hline 12. Jljin-on & $36^{\circ} 45^{\prime}$ & $129^{\circ} 20^{\prime}$ & 200 & \\
\hline 13. Youngwol & $37^{\circ} 18^{\prime}$ & $128^{\circ} 19^{\prime}$ & 300 & \\
\hline 14. Joengwon & $37^{\circ} 02^{\prime}$ & $127^{\circ} 50^{\prime}$ & 150 & \\
\hline 15. Neunkyung & $36^{\circ} 47^{\prime}$ & $128^{\circ} 18^{\prime}$ & 400 & \\
\hline 16. Boeun & $36^{\circ} 3 !^{\prime}$ & $127^{\circ} 50^{\prime}$ & 250 & \\
\hline 17. Jinan & $35^{\circ} 45^{\prime}$ & $127^{\circ} 20^{\prime}$ & 300 & \\
\hline 18. Atndong & $36^{\circ} 32^{\prime}$ & $128^{\circ} 50^{\prime}$ & 200 & \\
\hline 19. Sunfat & $36^{\circ} 16^{\prime}$ & $128^{\circ} 20^{\prime}$ & 150 & \\
\hline 20. Taean & $36^{\circ} 31^{\prime}$ & $126^{\circ} 2 l^{\prime}$ & 50 & \\
\hline 21. Chungyang & $36^{\circ} 30^{\prime}$ & $126^{\circ} 50^{\prime}$ & 200 & \\
\hline 22. Wanju & $35^{\circ} 55^{\prime}$ & $127^{\circ} 15^{\prime}$ & 150 & \\
\hline 23. Youngl & $36^{\circ} 15$ & $129 \% 2 !^{\prime}$ & 250 & \\
\hline 24. Kyungiu & $35^{\circ} 45^{\prime}$ & $129^{\circ} 20^{\prime}$ & 100 & \\
\hline 25. Youngchur & $36^{\circ} 02^{\prime}$ & $128^{\circ} 50^{\prime}$ & 200 & \\
\hline 26. Kolyung & $35^{\circ} 45^{\prime}$ & $128^{\circ} 20^{\prime}$ & 150 & warm-lemperale \\
\hline 27. Nityang & $35^{\circ} 30^{\prime}$ & $128 \circ 51^{1}$ & 150 & \\
\hline 2x. EIaman & $35^{\prime} 15$ & $128^{\circ} 20^{\prime}$ & 150 & \\
\hline 29. Виมп & $35^{\circ} 42^{\prime}$ & $126^{\circ} 36^{\prime}$ & 100 & \\
\hline 30. Haunyang & $35^{\circ} 30^{\prime}$ & $127^{\circ} 49^{\prime}$ & 200 & \\
\hline 31. Jungiu & $35^{\circ} 30^{\prime}$ & $126^{\circ} 50$ & 100 & \\
\hline 32. Koksung & $35^{\circ} 16^{\prime}$ & $127 \% 1 \%$ & 150 & \\
\hline 33. Naj] & $35^{\circ} 01^{\prime}$ & $126^{\circ} 50^{\prime}$ & 50 & \\
\hline 34. Fadong & $\left.35^{\circ} 0\right]^{\prime}$ & $127^{\circ} 52^{\prime}$ & 50 & \\
\hline 35. Haenam & $3403 ! \prime$ & $126^{\circ} 31^{\prime}$ & 150 & sub-troplcal \\
\hline 36. Seogtipo & $33^{\circ} 20^{\prime}$ & $126^{\circ} 30^{\prime}$ & 1250 & \\
\hline
\end{tabular}


this approach, the interpretation of the genotype pattern obtained when genotype regression coefficients are plotted against genotype mean values. The non-parametric approaches of genotype by environment interactions are based on the concept of analyzing relative ranks of genotypes in different environments. In nonparametric approaches, no assumption is required about mathematical distribution of analyzed values, homogeneity of variances and additivity of effects (HüHN, 1966). The basic concept of multivariate analysis is to explain the multidimensional variation by a reduced number of dimensions has been used to characterize and understand genotype by environment interactions in the form of pattern of relationship among genotypes which perform uniformly across environments (CHAHAL and GosAL, 2002). There are some statistical and biological criticisms and limitations in these four approaches above mentioned (PSWARAYI et al., 1997; CHAHAL and Gosal, 2002; AlBerTs, 2004). Thus, it is considered that $\mathrm{GxE}$ interaction was detected and quantified using two or more approaches together.

This study was conducted to examine 1) the magnitude of provenance by environment interaction, 2) the response pattern of provenances to environments and 3) to select the suitable seed sources for reforestation of P. densiflora.

\section{Materials and Methods}

To examine GxE interaction and stability of $P$. densiflora provenances, data were collected from eleven provenance trials established by Korea Forest Research Institute in 1996 with 36 provenances (Table 1). The seed sources were systematically selected to cover whole geographic range of $P$. densiflora, i.e., a point of intersection between latitudinal and longitudinal line was selected as a sampling site (HYUN and HAN, 1994). The planting sites were also selected in similar manner (Table 2). The field trials were established with a ran- domized complete block design with five replications. Each provenance was planted in 10-tree row plot in each block and at a spacing of $1.8 \mathrm{~m} \times 1.8 \mathrm{~m}$. The data of height growth was obtained from measurement at age 6 .

Data set was analyzed with a linear regression model (FINLAY and WILKINSON, 1963) and AMMI (additive main effect and multiplicative interaction) models (GAUCH and ZOBEL, 1988) to evaluate adaptability and stability of $P$. densiflora provenances at different environments.

Simple linear regression provides a conceptual model for genotype stability and is the most widely used statistical technique in plant breeding (HAYWARD et al., 1993). In this approach, the components of $\mathrm{GxE}$ interactions are linearly related to environmental effects measured as the average performance of all test genotypes for the character under consideration (FINLAY and WILKINSON, 1963). The estimates of linear regression and the genotypic means are then used to indicate the adaptive property of each genotype (CHAHAL and GOSAL, 2002). The linear regression model is:

$$
Y_{i j}=\mu+g_{j}+E_{j}+b_{i} E_{j}+e_{i j}
$$

where $Y_{i j}$ is the mean of provenance $i$ in environment $j$; $\mu$ is the general mean; $g_{i}$ is the mean of provenance $i$ over all environment; $E_{j}$ is the environmental index for environment $j\left(\mathrm{Y}_{. j}-\mathrm{Y}_{.}.\right) ; b_{i}$ is the slope of regression specific for provenance $i$; and $e_{i j}$ is the residual variation which is assumed to be zero for the values averaged over replications. The provenances and test sites were regarded as random effect because the provenances and test sites were sampled at random as mentioned above. So the provenance and site effect were tested against the interaction mean square.

AMMI model is a multivariate approach to analyze $\mathrm{GxE}$ interaction. AMMI extracts genotype and environment main effects, then uses principal component analysis to explain patterns in the $\mathrm{GxE}$ or residual matrix (HAYWARD et al., 1993).

Table 2. - The location of 11 test sites of Pinus densiflora provenance trials.

\begin{tabular}{|c|c|c|c|c|}
\hline \multirow{2}{*}{ Test site } & \multicolumn{3}{|c|}{ Location } & \multirow{2}{*}{ Forest zone } \\
\hline & Lat (N) & $\operatorname{Long}(W)$ & Alt.(m) & \\
\hline Jungsun (JS) & $37^{\circ} 27^{\prime}$ & $128^{\circ} 42^{x}$ & 380 & \multirow{2}{*}{ cosl-temperate } \\
\hline Bongwha ( $\mathrm{BW}$ ) & $37^{\circ} 04^{\prime}$ & $128^{\circ} 49^{r}$ & 650 & \\
\hline Chunchun (CC) & $37^{\circ} 55$ & $127^{\circ} 44^{\prime}$ & 60 & \multirow{4}{*}{ mid-temperate } \\
\hline Whasung (WS) & $37^{\circ} 13^{\prime}$ & $126^{\circ} 56^{\prime}$ & 60 & \\
\hline Chungiu (CJ) & $36^{\circ} 53^{\prime}$ & $127^{\circ} 57^{r}$ & 160 & \\
\hline Gongiu (GJ) & $36^{\circ} 37$ & $127^{\circ} 06^{r}$ & 190 & \\
\hline Tacan (TA) & $36^{\circ} 28^{\circ}$ & $126^{\circ} 22^{r}$ & 20 & \multirow{3}{*}{ waren-tcmperate } \\
\hline Kyungju (KJ) & $35^{\circ} 57^{\prime}$ & $129^{\circ} 05^{\prime}$ & 180 & \\
\hline Naju (NJ) & $35^{\circ} 01^{r}$ & $126^{\circ} 50^{r}$ & 100 & \\
\hline Jinju (III) & $35^{\circ} 08^{r}$ & $128^{\circ} 18^{r}$ & 70 & \multirow{2}{*}{ sub-tropical } \\
\hline Jcju (JE) & $33^{\circ} 10^{r}$ & $126^{\circ} 40^{x}$ & 390 & \\
\hline
\end{tabular}


Table 3. - ANOVA for height growth with site regression.

\begin{tabular}{lcccc}
\multicolumn{1}{c}{ Source } & D.F. & MS & F<P & $\%$ of SS \\
Site (S) & 10 & 20506.7 & $<0.0001$ & 89.5 \\
Provenance (P) & 35 & 225.195 & $<0.0001$ & 3.4 \\
Provenancex Site & 350 & 46.6760 & & 7.1 \\
PxS Regression & 35 & 73.8916 & $<0.011$ & $(15.8)$ \\
Deviations & 315 & 43.6521 & & $(84.2)$ \\
Total & 395 & & & 100.0
\end{tabular}

The AMMI model for the average yield, over replicates of the $i$ th genotype in the $j$ th environment is:

$$
Y_{i j}=\mu+G_{j}+E_{j}+\sum_{n=1}^{N} \lambda_{j} \gamma_{i r} \delta_{j n}+e_{i j}
$$

where $Y_{i j}$ is the yield of $i$ th genotype in $j$ th environment; $\mu$ is the overall mean; $G_{i}$ is the genotypic ( $i$ th) main effect; $E_{j}$ is the environmental (jth) main effect; $\lambda_{i}$ is the singular value of $n$th PCA axis; $\gamma_{i n}$ is the genotypic eigen vector values for $n$th PCA axis; $\delta_{j n}$ is the environmental eigen vector values for $n$th PCA axis; and $e_{i j}$ is the resid- ual. The AMMI analysis was conducted using IRRISTAT program (InTERNATIONAL RICE RESEARCH Institute, 2004).

\section{Results and Discussion}

\section{Stability from regression analysis}

According to linear regression model, provenance by site interaction effect was significant for height growth $(\mathrm{p}<0.011)$. The interaction term explained $7.1 \%$ of the total variation (Table 3). Most variation was attributed

Table 4. - The height mean of provenances, slopes of regression of provenance means on site index and standard error of slopes.

\begin{tabular}{|c|c|c|c|c|c|c|c|}
\hline Provenance & $\begin{array}{l}\text { Mean } \\
\text { (cm) }\end{array}$ & Slope & St, & Provenance & $\begin{array}{l}\text { Mean } \\
(\mathrm{cm})\end{array}$ & Slope & SE: \\
\hline 1. Inje & 102.4 & $1.19^{*}$ & 0.066 & 19. Sunsan & 90.4 & 0.92 & 0,090 \\
\hline 2. Whachun & 97.2 & 1.11 & 0.089 & 20. Taean & 101.3 & 1.11 & 0.076 \\
\hline 3. I Iongchun & 98.7 & 1.13 & 0.113 & 21. Chungyang & 91.2 & 0.93 & 0.078 \\
\hline 4. Jungsun & 98.4 & $1.23^{*}$ & 0.062 & 22. Wanju & 93.2 & 1.03 & 0.091 \\
\hline 5. Bongwha & 100.9 & $1.16^{*}$ & 0.125 & 23. Youngil & 92.4 & 0.87 & 0.109 \\
\hline 6. Yoonchun & 89.2 & 1.10 & 0.087 & 24. Kyungju & 93.4 & 0.91 & 0.068 \\
\hline 7. Hungsung & 97.5 & 0.96 & 0.091 & 25. Youngchur & 91.0 & 1.02 & 0.083 \\
\hline 8. Ichun & 84.4 & 0.87 & 0.096 & 26. Koryung & 92.7 & $0.83^{*}$ & 0.062 \\
\hline 9. Chutian & 85.7 & 0.96 & 0.092 & 27. Milyang & 92.9 & 0.98 & 0.099 \\
\hline 10. Samchuk & 959 & 1.06 & 0.055 & 28. Haman & 969 & 0.95 & 0.057 \\
\hline 11. Uljin-seo & 94.0 & 1.06 & 0.136 & 29. Buan & 97.1 & 0.87 & 0.092 \\
\hline 12. UIjjin-on & 85.7 & 0.97 & 0.096 & 30. Harnyang & 87.2 & $0.86^{*}$ & 0.043 \\
\hline 13. Youngwol & 96.6 & 1.00 & 0.084 & 31. Juпgiu & 9.4 & 1.01 & 0.118 \\
\hline 14. Joongwon & 90.9 & 1.02 & 0.067 & 32. Koksung & 89.2 & 0.91 & 0.057 \\
\hline 15. Munkyung & 97.7 & 1.01 & 0.081 & 33. Naju & 92.2 & 0.94 & 0.069 \\
\hline 16. Bocun & 88.8 & 0.92 & 0.056 & 34. Hadong & 93.6 & 0.90 & 0.076 \\
\hline 17. Jinan & 92.0 & 0.88 & 0.056 & 35. Наспаm & 95.7 & 1.13 & 0.085 \\
\hline 18. Ardong & 90.8 & 0.92 & 0,090 & 36. Seoguipo & 99.1 & $1.29 *$ & 0.116 \\
\hline
\end{tabular}

*: indicates slopes were significantly different from the slope for the overall regression of 1.0. 
to environment effect $(89.5 \%)$. Among the variance of GxE interaction, $15.8 \%$ was explained by the regression analysis which was based on regression of provenance performance on a environmental index. The residual $\mathrm{GxE}$ interaction was attributed to random deviations. The regression coefficients of each provenance are presented in Table 4. Most of the provenances were not significantly different from the slope for the overall regression of 1.0, except for Inje (1), Bongwha (5), Jungsun (4), Koryung (26), Hamyang (30) and Seoguipo (36).

FinLAY and WiLKINSON (1963) developed an index that measures adaptation and sensitivity of a given genotype to environments. Using this approach, a linear regression of phenotypic value on the environmental value was calculated for each provenance. The regression coefficient thus obtained will show the "response" or "sensitivity" to changing environments. To determine adapt- ability, however, the interpretation has always to be associated with the provenance mean. When the regression coefficient of a provenance is 1.0 and the provenance has a mean above the overall average, the provenance is well adapted to all environments. If the mean of the provenance is below the overall mean and the regression coefficient is 1.0 , the provenance is poorly adapted to all environments. Regression coefficients above 1.0 indicate genotypes with a response above average to high yielding environments. Regression coefficients below 1.0 provide a measure of below average responses to high yielding environments.

The slope of regression was plotted against the provenance mean height (Figure 1). The slopes of Inje (1), Bongwha (5), Jungsun (4) and Seoguipo (36) were significantly higher than unity suggesting above average response to high yielding environments. Since this was

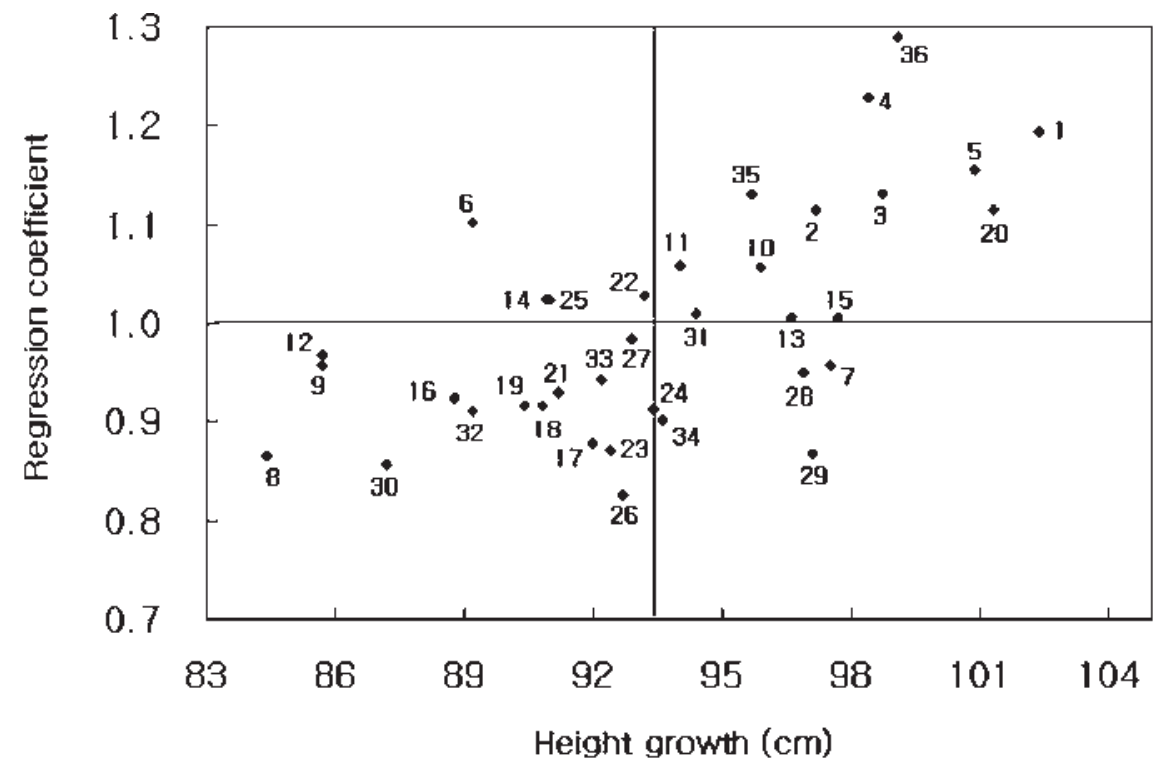

Figure 1. - Regression coefficient plotted against the mean height growth. The abbreviation and number represent the test sites and the provenances as shown in Table 1 . The vertical line is the grand mean of the experiment and the horizontal line is $\mathrm{b}=1.0$.

Table 5. - Combined ANOVA with AMMI model for height growth.

\begin{tabular}{lrrrrr}
\multicolumn{1}{c}{ Source } & DF & \multicolumn{1}{c}{ SS } & MS & r-value & $\%$ of PxS SS \\
Site & 10 & 205067 & 20506 & & \\
Provenance & 35 & 7881 & 225 & & \\
Provenance x Site & $\$ 50$ & 16336 & 46 & & \\
IPCA 1 & 44 & 4953 & 112 & $3.026 * *$ & $(30.3)$ \\
IPCA 2 & 42 & 3147 & 74 & $2.402 * *$ & $(19.3)$ \\
IPCA 3 & 40 & 2383 & 59 & $2.281 * *$ & $(14.6)$ \\
IPCA 4 & 38 & 1747 & 45 & $2.083 * *$ & $(10.7)$ \\
PXS Residual & 186 & 4105 & 22 & & $(25.1)$ \\
Total & 395 & 229285 & & & \\
\hline
\end{tabular}

**: significant at the $0.01 \%$ level. 
combined with a mean above average these provenances are well adapted to high yielding environments. The Koryung (26) and Hamyang (30) showed less sensitive response to high yielding environments $(b<1.0)$. It would be considered well adapted to unfavorable environments. Among the provenances with unity slope $(b=1.0)$, Taean (20) and Hongchun (3) showed high height growth. It means that they are well adapted to all environments. Ichun (8), Chunan (9) and Uljin-on (12) showed low height growth. It means that they are poorly adapted to all environments. Jungju (31), Youngwol (13) and Munkyung (15) showed most stable adaptability to most of the environments.

According to these results, Taean (20) and Hongchun (3) may be preferred as seed sources for reforestation of $P$. densiflora, because they are well adapted to all environments with greater height growth. To maximize genetic gain, however, selecting separate provenances specific for favorable, poor or average environments may also be an efficient strategy.

\section{Adaptability from AMMI model}

The combined ANOVA with AMMI model results for height growth is shown in Table 5. While the regression model accounted for $15.8 \%$ of $\mathrm{GxE}$ interaction terms, the AMMI model accounted for $74.9 \%$ with four PCA components. The AMMI model provides a more adequate biological explanation of $\mathrm{Gx} \mathrm{E}$ than regression. Thus, these four IPCAs (principal component scores of the interaction) containing $\mathrm{GxE}$ variation can be used to interpret the adaptation of tested provenances in specific regions or all regions (GAUCH, 1988).

The AMMI analysis also provides a graphical representation or biplot to summarize information on the main effects and first principal component scores of the interaction of both genotypes and environments simul- taneously (KEMPTON, 1984). The biplot helps to visualize relationship between eigenvalues for PCA1, genotypic and environment means. Genotype with a PCA1 value close to zero suggests general adaptation to the tested environments (Fox et al., 1997). A large genotypic PCA1 reflects more specific adaptation to environments with PCA1 score of the same size. The genotypes and environments with PCA values of same sign show positive interaction suggesting adaptation of genotypes in those environments. The reverse sign of PCA value of genotypes and environments depicts negative interaction i.e. poor performance of genotypes in such environment (CHAHAL and Gosal, 2002).

In Figure 2, the IPCA 1 scores for both the provenances and the test sites were plotted against the mean height growth for the provenances and the test sites. High variation in mean height growth was observed among the test sites. The test sites in quadrant I and III are low yielding environments, whereas sites in quadrant II and IV are high yielding environments. The high yielding environments were Whasung (WS), Chunchun (CC), Naju (NJ) and Bongwha (BW). The low yielding environments were Taean (TA), Gongju (GJ), Jungsun (JS) and Jinju (JJ).

Inje (1), Taean (20), Bongwha (5) and Seoguipo (36) were specifically adapted to the higher yielding environments. Considering only the IPCA 1 scores, Bongwha (5), Seoguipo (36) and Hongchun (3) were the most unstable provenances and also adapted to the higher yielding or more favorable environments. Heungsung (7), Samchuk (10), Munkyung (15) and Jungju (31) showed general adaptation to the tested environments.

Since IPCA 2 scores also play a significant role in explaining the GxE interaction, the IPCA 1 scores were plotted against the IPCA 2 scores to further explore adaptation (Figure 3). Buan (29), Whachun (2), Sam-

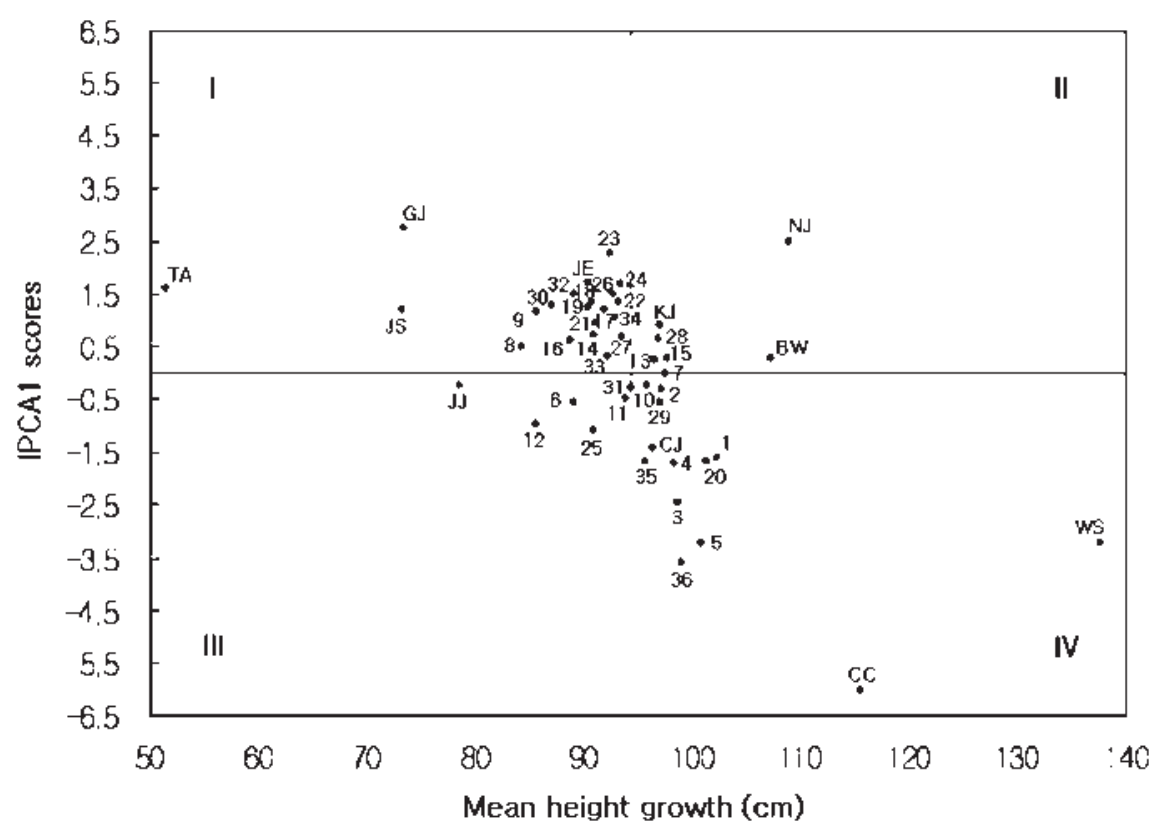

Figure 2. - Biplot of mean height $(\mathrm{cm})$ and the first PCA axis for interaction of 36 provenances at 11 test sties. The abbreviation and number indicates test sites and provenances as shown in Table 1 and 2 . The vertical line is the grand mean of experiment and the horizontal line is $\mathrm{PCA}=0$. 


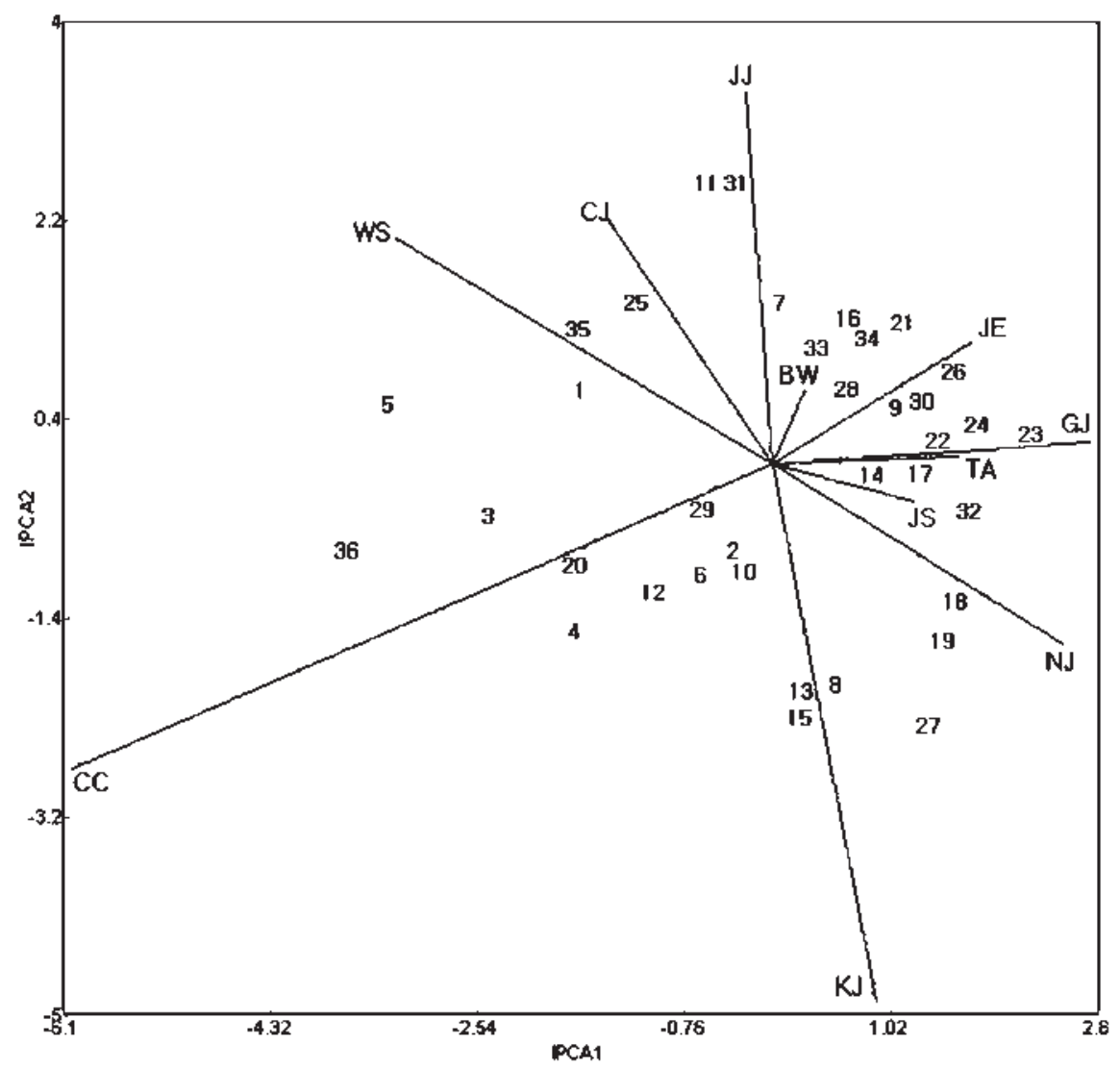

Figure 3. - Interaction biplot for the AMMI 2 model on height growth. The abbreviation and number represent the test sites and the provenances as shown in Table 1 and 2 .

chuk (10) and Joongwon (14) were more stable, when plotting the IPCA 1 and IPCA 2 scores. Other provenances were unstable and adapted to the specific environments. For example, Seoguipo (36), Bongwha (5), Hongchun (3), Jungsun (4) and Taean (20) showed high adaptability in Chunchun (CC) plantation. In Jeju (JE) plantation, Hamyang (30), Hadong (34), Koryung (26) and Chungyang (21) provenances showed high adaptability. For other test sites, the best provenances with high adaptability could be selected in similar manners.

\section{Implication of $G x E$ interaction}

In Korea, $P$. densiflora is classified into six ecotypes, i.e. northeastern, Geumgang, central south flatland, central south highland, Angang and Uibong type. These ecotypes were proposed by UYEKI (1928) based on their tree form and the growth characteristics. Particularly, Geumgang type, native to Taebaek mountain range in Korea, has superior wood properties and stem straightness.

Among provenances tested in this study, Bongwha (5), Uljin-seo (11) and Uljin-on (12) are from the region of Geumgang. Bongwha (5) showed greater height growth than other provenances at most test sites except for Kyungju (KJ) and Naju (NJ). Uljin-seo (11) showed average growth performance, while Uljin-on (12) showed lower height growth at all test sites.

According to linear regression analysis, Uljin-seo (11) and Uljin-on (12) showed average stability $(b=1.0)$ with average and low height growth, respectively. Uljin-seo (11) was the most stable adapted to most of the environments while Uljin-on (12) was poorly adapted to all environments. The regression coefficient of Bongwha (5) was significantly higher than unity and showed greater height growth. Bongwha (5) tends to have sensitive response to environmental variation and great specific adaptability to high yielding environments (Figure 1). Similar tendency of Bongwha (5) can be seen in Figure 2 . There was high correlation between regression coefficient and IPCA 1 scores $(r=-0.84)$. Therefore, the seed transfer of Geumgang source to other regions should be carried out with caution. Similarly, although Taean (20) and Hongchun (3) were well adapted to all environments with greater height growth, the seed transfer to other regions should be carefully managed from genetic conservation point of view and due to the ages of the experiments as experienced with earlier seed transfers. Following UYEKI (1928), seed movement of Geumgang provenances to other regions was suggested to produce high quality wood. In 1980's, test trials were established to examine the growth response of Geumgang provenances to various environments. At age 6, Geumgang source showed high growth performance in all test sites (KIM and HAN, 1997). The researchers tentatively concluded that it was possible to use Geumgang provenances in other regions. At age 18, however, the performance of Geumgang provenances was lower than that of other provenances at the test sites in warm-temperate 
zone (not published). Thus, it was suggested that the long-term monitoring was required to determine a provenance performance.

The tentative seed transfer zones of forest trees in Korea was proposed by CHOI et al. (1999). They classified the seed transfer zones into 19 categories based on the data of forest zones and climatic factors in Korea. There are numerous studies on the relationship between climate of the seed sources and their growth performance at test site. The factors affecting growth performance in the tests were latitude in Scots pine (PERSSON and StAHL, 1993), yearly minimum temperature (SchmidtLING, 2001) in Southern pine, winter coldness and length of growing season in Sitka spruce (XU et al., 2000). For P. densiflora, KIM et al. (2005) reported that the height growth of provenances in the test sites was mainly explained by latitude, extreme high temperature (Nov. Feb.), extreme low temperature (Dec. Feb.) and annual mean growing days of the seed sources. They also reported that the local seed sources showed relatively high growth performance and adaptability. REHFELDT et al. (1999) suggested that optimizing the growth and survival rate was dependent on matching provenance and planting site climates for the general temperature regime, the coldness of the winter, the strength of continental effects and the balance between temperature and precipitation.

Although some meaningful results were obtained from this study, the results are not conclusive because the analyzed data were from an early stage of experiments. Early growth assessments may not be reliable for assessing GxE at maturity (GwAZE et al., 2001; YEISER et al., 2001). This implies a critical need to evaluate $\mathrm{GxE}$ at mature ages in forest trees. Therefore, longterm monitoring of growth and survival performance is required, until mature age. In addition, studies on the relationship between adaptive traits and environments are required to delineate seed zone and achieve advanced breeding for $P$. densiflora.

\section{References}

AlBerts, M. J. A. (2004): A comparison of statistical method to describe genotype $\mathrm{x}$ environment interaction and yield stability in multi-location maize trials. M. S. Dissertation. University of the Free State. South Africa. 96pp.

CARSON, S. D. (1991): Genotype x environment interaction and optimal number of progeny test sites for improving Pinus radiata in New Zealand. N. Z. J. For. Sci. 21: 32-49.

Chahal, G. S. and S. S. Gosal (2002): Principles and Procedures of Plant Breeding. Alpha Science International Ltd. London.

ChOI, W. Y., W. S. TAK, K. B. YIM and S. S. JANG (1999): Delineation of provenance regions of forests based on climate factors in Korea. J. Kor. For. Soc. 88: 379-388.

DiCKERSON, G. E. (1962): Implications of genetic-environment interactions in animal breeding. Animal Production 4: 47-63.

Finlay, K. W. and G. N. Wilkinson (1963): The analysis of adaptation in a plant-breeding programme. Aust. J. Agric. Res. 14: 742-754.
Fox, P. N., J. Crossa and I. Ramagosa (1997): Multi-environmental testing and genotype $\mathrm{x}$ environment interaction, pp. 117-138 in Statistical methods for plant variety evaluation, edited by R. A. KEMPTON and P. N. Fox, Chapman and Hall, London.

GAUCH Jr., H. G. (1988): Model selection and validation for yield trials with interaction. Biometrics 44: 705-715.

GaUCH, H. G. and R. W. ZoBeL (1988): Predictive and postdictive success of statistical analyses of yield trials. Theor. Appl. Genet. 75: 1-10.

Gwaze, D. P., J. A. Wolliams, P. J. Kanowski and F. E. BRIDGWATER (2001): Interactions of genotype with site for height and stem straightness in Pinus taeda in Zimbabwe. Silvae Genetica 50: 135-140.

HAYward, M. D., N. O. Bosemark and I. Romagosa (1993): Plant Breeding - Principles and prospects. Chapman \& Hall, Cambridge.

HüHN, M. (1996): Non-parametric analysis of genotype $x$ environment interactions by ranks., pp. 213-228 in Genotype by environment interaction, edited by M. S. KANG and H. G. GAUCH JR., CRC Press, Boca Raton, New York.

HYUN, J. O. and S. U. HAN (1994): A strategy for maximizing genetic variability in selection breeding program of Pinus densiflora S. et Z., pp. 101-115 in Conservation and manipulation of genetic resources in forestry, edited by Z. S. Kim and H. H. HatTemer, Kwang Moon Kag, Suwon.

INTERNATIONAL RICE RESEARCH INSTITUTE (2004): IRRISTAT ver. 4.4.

Johnson, G. R. and R. D. BuRdon (1989): Family-site interaction in Pinus radiata: implications for progeny testing strategy and regionalized breeding in New Zealand. Silvae Genet. 39: 55-62.

KEMPTON, R. A. (1984): The use of biplots in interpreting variety by environment interactions. Journal of Agricultural Sciences 103: 123-135.

KIM, I. S., K. O. RYU, J. H. Song and T. S. KIM (2005): Geographic variation in survival rate and height growth of Pinus densiflora S. et Z. in Korea. J. Kor. For. Soc. 94: 73-81.

KIM, J. H., I. S. Jung, W. H. LeE and S. C. Hong (2002): Studies on the fundamental properties of the wood of Gumgangsong (Pinus densiflora for. erecta Uyki) (Part 2). J. Kor. For. Soc. 91: 241-246.

KIM, K. S. and Y. C. HAN (1997): Variation in growth characteristics of Pinus densiflora S. et Z. at eight experimental plantations of Korea. J. Kor. For. Soc. 86: $119-127$.

KIM, Y. Y., J. O. HyUn, K. N. HonG, T. B. CHOI and K. S. KIM (1995): Genetic variation of natural populations of Pinus densiflora in Korea based on RAPD marker analysis. Kor. J. Breed. 27: 23-48.

LEE, C. Y. and B. H. Chо (2001): Pine, Pine Forest. Korea Forest Research Institute, Seoul.

LEE, S. W., Y. Y. KIM, J. O. HyUn and Z. S. KIM (1997): Comparison of genetic variation in Pinus densiflora natural populations by allozyme and RAPD analysis. Kor. J. Breed. 29: 72-83.

PARK, I. H. and S. M. LEE (1990): Biomass and net production of Pinus densiflora natural forests of four local forms in Korea. J. Kor. For. Soc. 79: 196-204.

Persson, B. and E. G. STAHL (1993): Effects of provenance transfer in an experiment series of Scots pine (Pinus sylvestris L.) in northern Sweden. Swed. Univ. Agric. Sci. Dep. For. Yield Res. Rep. 35pp. 
Pswarayi, I. Z., R. D. Barnes, J. S. Birks and P. J. KANOWSKI (1997): Genotype-environment interaction in a population of Pinus elliottii Engelm. var. elliottii. Silvae Genetica 46: 35-40.

Rehfeldt, G. E., N. M. Tchebakova and L. K. Barnhardt (1999): Efficacy of climate transfer functions: introduction of Eurasian populations of Larix into Alberta. Can. J. For. Res. 29: 1660-1668.

Schmidtling, R. C. (2001): Southern pine seed sources. Gen. Tech. Rep. SRS-XX. Asheville, NC: USDA, Forest Service, Southern Research Station. 25pp.

UYeKI, H. (1928): On the physiognomy of Pinus densiflora growing in Korea and silvicultural treatment for its improvement. Bull. of the Agr. and For. Coll. Suwon. Korea. 263pp.

ViANA, J. M. S. and C. D. CRUZ (2002): Analysis of stability and adaptability through different models of line regression. Cienc. agrotec. Lavras 26: 455-462.
XU, P., C. C. YING and Y. A. EL-Kassaby (2000): Multivariance analyses of causal correlation between growth and climate in Sitka spruce. Silvae Genetica 49: 257-263.

YEISER, J. L., J. P. VAN BUITENEN and W. LOWE (1981): Genotype $\mathrm{x}$ environment interactions and seed movements for loblolly pine in the western gulf region. Silvae Genetica 30: 196-200.

Yeiser, J. L., W. Lowe and J. P. van BuiJTENEN (2001): Stability and seed movement for loblolly pine in the western gulf region. Silvae Genetica 50: 81-88.

YIM, K. B. and K. J. LEE (1979): The variation of natural population of Pinus densiflora S. et Z. in Korea (IX) needle and wood characteristics of six populations. J. Kor. For. Soc. 44: 1-25.

\title{
Mixed Mating With Preferential Outcrossing in Acacia saligna (Labill.) H. Wendl. (Leguminosae: Mimosoideae)
}

\author{
By N. GeORGE ${ }^{1,3), *)}$, M. ByrnE ${ }^{2,3)}$ and G. YAN ${ }^{1)}$
}

(Received $15^{\text {th }}$ November 2006)

\begin{abstract}
Acacia saligna is being developed as an agroforestry crop for the southern agricultural regions of Australia. This study investigated the breeding system of A. saligna to generate basic knowledge for breeding and utilization of the species. Allozyme markers were used to investigate the mating system of four populations of the species. All the populations had high outcrossing rates, with a mean multilocus outcrossing rate of 0.91 . The implications of a highly outcrossed mating system to the utilization of $A$. saligna are discussed.
\end{abstract}

Key words: Acacia saligna, agroforestry, mating system, high outcrossing.

\section{Introduction}

The Acacia genus comprises over 1500 species with the greatest species diversity, approximately 955

\footnotetext{
1) School of Plant Biology, Faculty of Natural and Agricultural Sciences, The University of Western Australia, 35 Stirling Highway, Crawley, WA 6009, Australia.

$\left.{ }^{2}\right)$ Science Division, Department of Conservation and Land Management, Locked Bag 104, Bentley Delivery Centre, WA 6983, Australia.

$\left.{ }^{3}\right)$ Co-operative Research Centre for the Plant-based Management of Dryland Salinity, The University of Western Australia, 35 Stirling Highway, Crawley, WA 6009, Australia.

*) Corresponding Author. School of Plant Biology, Faculty of Natural and Agricultural Sciences, The University of Western Australia, 35 Stirling Highway, Crawley, WA 6009, Australia. Email: georgnicholas@gmail.com
}

species, being native to Australia (MASLIN et al., 2003). The majority of these species belong to the subgenus Phyllodineae (MASLIN et al., 2003). Many Acacia species have characteristics that make them suitable as crops, including the production of useful products such as timber, charcoal, panel board pulp, tannin and livestock feed and agronomically favourable characters like fast growth rates and tolerance to harsh environmental conditions (MASLIN and MCDonald, 2004). Consequently, there is interest in the potential for domestication of Australian Acacia as crops for low rainfall agroforestry in the agricultural regions of southern Australia.

An examination of 35 Australian Acacia found A. saligna (Labill.) H.L. Wendl. (subgenus Phyllodineae) to have good potential for utilization as a forage crop (MASLIN and McDonald, 2004). Acacia saligna is native to the south-west of Western Australian and is already used extensively around the world (MASLIN and McDonald, 2004). The species has many favourable characteristics but there is also variation in economically important traits, such as growth form, which may be problematic for utilization. This variation may have underlying genetic causes (GEORGE et al., 2007; GEORGE et al., 2006) so selection and breeding of more uniform improved cultivars of $A$. saligna could be utilized to enhance the value of the species as a forage crop.

The mating system of plants influences breeding methodology and agronomic practices (ALLARD, 1999; SImmonds and SmaRTT, 1999). Despite the large number 